\section{Muscling up on Myozyme}

\section{By Tim Fulmer, Senior Writer}

Oxyrane U.K. Ltd. and BioMarin Pharmaceutical Inc. have separately reported on their next-generation enzyme replacement therapies for Pompe's disease. Both molecules cleared glycogen from mouse muscle better than the marketed drug Myozyme from Sanofi. ${ }^{1,2}$ BioMarin has moved its therapy into a Phase I/II trial, whereas Oxyrane is carrying out IND-enabling animal toxicology studies.

Pompe's disease is an inherited disorder of glycogen metabolism caused by an absence of or deficiency in the lysosomal enzyme acid $\alpha$-glucosidase (GAA). The resulting accumulation of glycogen in cardiac and skeletal muscle leads to severe and progressive muscle weakness, cardiomyopathy and respiratory failure.

Sanofi's Genzyme Corp. unit markets the enzyme replacement therapy Myozyme and Lumizyme to treat the disease.

The problem is that skeletal muscle cells are less accessible to systemic enzyme replacement therapy than cells targeted in other lysosomal storage diseases. Indeed, the drugs are typically delivered at doses 20-30 times higher than other enzyme replacement therapies. ${ }^{3}$ These high doses can lead to long infusion times and adverse reactions, including fever, tachycardia, cyanosis and hypotension. ${ }^{4}$

Thus, Oxyrane and BioMarin have been modifying GAA to improve its uptake into skeletal muscle and make possible the use of lower doses.

Both companies focused on modifying GAA to increase its affinity for the insulin-like growth factor 2 receptor (IGF2R; M6PR), which mediates uptake of GAA and other lysosomal enzymes into the muscle cell. The Oxyrane group used carbohydrate modifications, whereas the BioMarin researchers used a peptide modification (see Figure 1, "Nextgeneration Myozyme”).

The Oxyrane group hypothesized that enhancing levels of the carbohydrate mannose-6-phosphate (M-6-P) on the surface of GAA would increase its uptake by muscle cells. The binding of M-6-P to

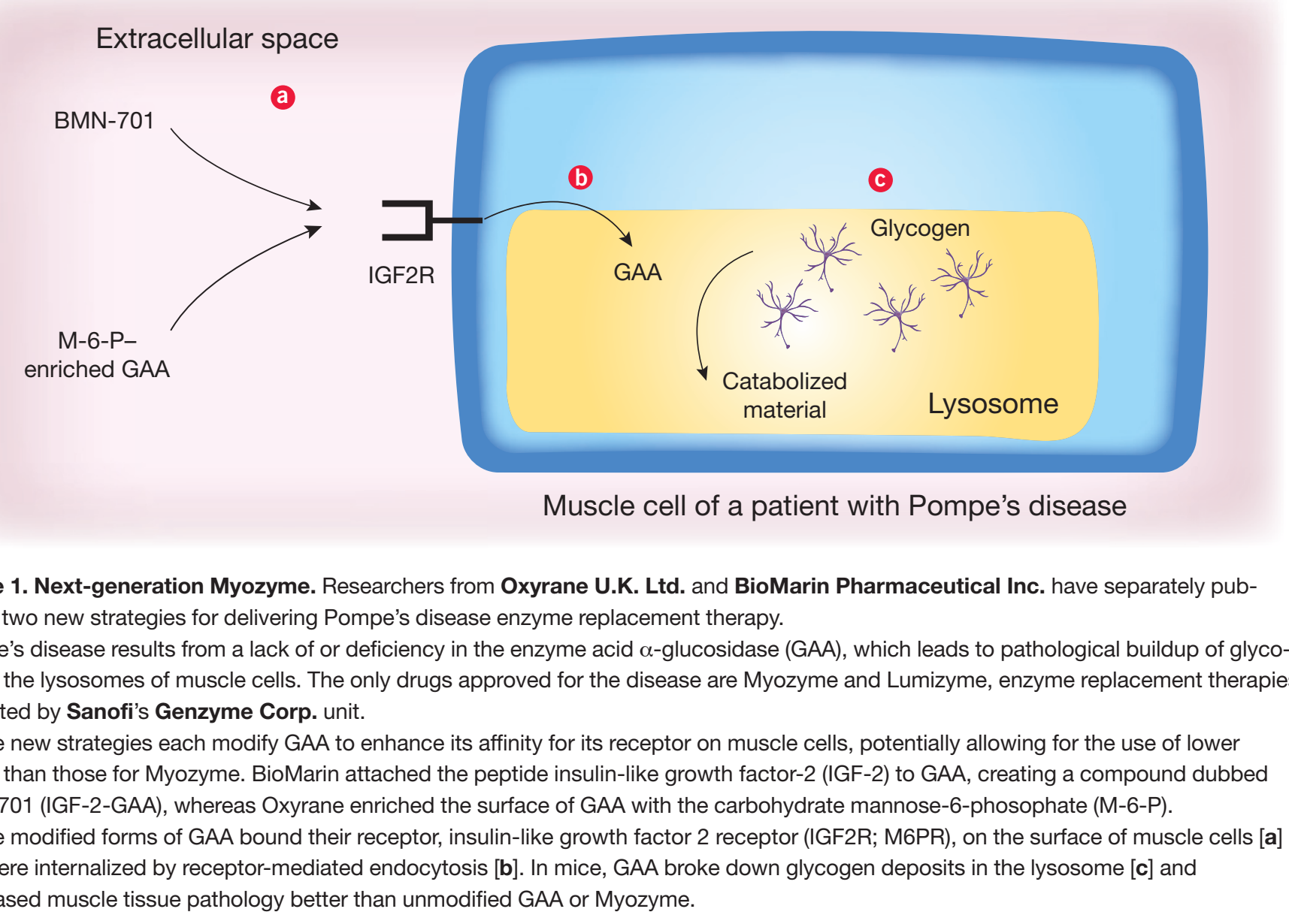


IGF2R is known to mediate delivery of proteins to the lysosome..$^{5-7}$

Oxyrane used the yeasts Yarrowia lipolytica and Pichia pastoris to produce modified GAA. In prior work, Oxyrane researchers and colleagues had engineered those yeast to yield much higher levels of carbohydrate modifications than the mammalian cell lines used to produce Myozyme and Lumizyme. ${ }^{8,9}$

In the new paper, the group showed that the resulting carbohydrateenriched GAA was purified from the yeast and treated with two processing enzymes to generate the final M-6-P-modified GAA, which had more than 15-fold higher M-6-P content than unmodified GAA.

Importantly, those higher M-6-P levels led to greater uptake of GAA by cultured fibroblasts from patients with Pompe's disease than uptake of unmodified GAA.

Finally, in a mouse model of Pompe's disease, the M-6-P-enhanced GAA cleared more glycogen from heart and thigh muscle than unmodified GAA.

The BioMarin group expected that linking a high-affinity endogenous ligand of IGF2R to GAA would increase uptake of the enzyme into muscle cells. Thus, they tagged GAA with a portion of insulin-like growth factor-2 (IGF-2), a ligand previously shown by some of the same BioMarin researchers to promote uptake of the lysosomal enzyme $\beta$-glucuronidase into fibroblasts. ${ }^{10}$

The tagged GAA, dubbed BMN-701 (IGF-2-GAA) was produced in mammalian cells, purified and shown to have the same enzymatic activity as untagged GAA. Moreover, BMN-701 showed greater uptake by rodent fibroblasts than Myozyme.

In mice with Pompe's disease, BMN-701 increased clearance of

"The IGF-2 tagging approach doesn't rely on posttranslational carbohydrate modifications, which can be difficult to control in largescale bioreactors and could lead to regulatory challenges." - Jonathan LeBowitz, BioMarin Pharmaceuticals Inc. glycogen from the heart, diaphragm and multiple skeletal muscles compared with Myozyme.

The Oxyrane and BioMarin findings were published in Nature Biotechnology and The Journal of Biological Chemistry, respectively.

\section{Pompe and circumstance}

BMN-701 is in an ongoing Phase I/II trial, with top-line data expected in 1Q13, corresponding author and BioMarin staff scientist Jonathan LeBowitz told SciBX.

"We think it is possible that BMN-701 could achieve the same clinical benefit in patients as Myozyme but at lower doses. However, there is also the possibility, which is our current hope, that BMN-701 will show greater clinical benefit than the marketed drug at comparable higher doses," he said.

A potential advantage of BMN-701 over carbohydrate-modified GAA, said LeBowitz, is that "the IGF-2 tagging approach doesn't rely on post-translational carbohydrate modifications, which can be difficult to control in large-scale bioreactors and could lead to regulatory challenges."

Indeed, differences in carbohydrate modifications of Myozyme produced in a 4,000-liter bioreactor versus enzyme produced in the original 160-liter bioreactor led the FDA to require a separate approval for the drug at the higher scale. The resulting product is marketed as Lumizyme. $^{11}$

Oxyrane's M-6-P-enriched GAA "is currently in the midst of sixmonth chronic animal toxicology studies, having successfully completed a four-week pilot toxicology study," corresponding author and Oxyrane CTO Wouter Vervecken told SciBX.

The company intends "to submit an IND next year with a view to advancing the product into Pompe's disease trials," he said. He declined to provide additional details on the timeline.

He added that Oxyrane's manufacturing process "is robust and scalable, and the company is already producing material based on fermentation at the 35-cubic-meter scale."

BioMarin and Oxyrane have patents covering their respective findings and therapies.

Fulmer, T. SciBX 5(48); doi:10.1038/scibx.2012.1250

Published online Dec. 13, 2012

\section{REFERENCES}

1. Tiels, P. et al. Nat. Biotechnol.; published online Nov. 18, 2012; doi:10.1038/nbt.2427

Contact: Wouter Vervecken, Oxyrane U.K. Ltd., Manchester, U.K. e-mail: wvervecken@oxyrane.com

Contact: Nico Callewaert, Flanders Institute for Biotechnology

(VIB), Ghent, Belgium

e-mail: nico.callewaert@dmbr.vib-ugent.be

Contact: Han Remaut, same affiliation as above e-mail: han.remaut@vib-vub.be

2. Maga, J.A. et al. J. Biol. Chem.; published online Nov. 27, 2012; doi:10.1074/jbc.M112.438663

Contact: Jonathan H. LeBowitz, BioMarin Pharmaceuticals Inc., Novato, Calif.

e-mail: jlebowtiz@bmrn.com

3. McVie-Wylie, A.J. et al. Mol. Genet. Metab. 94, 448-455 (2008)

4. Fulmer, T. BioCentury 19(50), A9-A10; Dec. 12, 2011

5. Dahms, N.M. et al. J. Biol. Chem. 264, 12115-12118 (1989)

6. Hille-Rehfeld, A. Biochim. Biophys. Acta 1241, 177-194 (1995)

7. York, S.J. et al. J. Biol. Chem. 274, 1164-1171 (1999)

8. Vervecken, W. et al. Appl. Environ. Microbiol. 70, 2639-2646 (2004)

9. De Pourcq, K. et al. Microb. Cell Fact. 11, 53; published online May 1, 2012; doi:10.1186/1475-2859-11-53

10. LeBowitz, J.H. et al. Proc. Natl. Acad. Sci. USA 101, 3083-3088 (2004)

11. Usdin, S. BioCentury 16(19), A1-A3; April 28, 2008

\section{COMPANIES AND INSTITUTIONS MENTIONED}

BioMarin Pharmaceutical Inc. (NASDAQ:BMRN), Novato, Calif. Genzyme Corp., Cambridge, Mass.

Oxyrane U.K. Ltd., Manchester, U.K.

Sanofi (Euronext:SAN; NYSE:SNY), Paris, France 